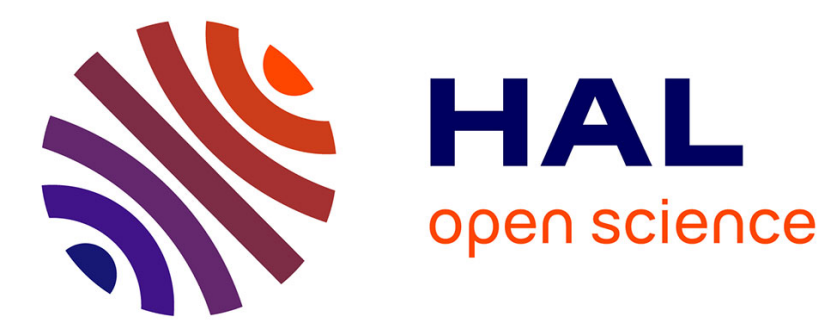

\title{
Effect of cropping systems and crop rotations on weeds
}

Alireza Koocheki, Mehdi Nassiri, Leila Alimoradi, Reza Ghorbani

\section{To cite this version:}

Alireza Koocheki, Mehdi Nassiri, Leila Alimoradi, Reza Ghorbani. Effect of cropping systems and crop rotations on weeds. Agronomy for Sustainable Development, 2009, 29 (2), pp.401-408. hal-00886470

\section{HAL Id: hal-00886470 \\ https://hal.science/hal-00886470}

Submitted on 1 Jan 2009

HAL is a multi-disciplinary open access archive for the deposit and dissemination of scientific research documents, whether they are published or not. The documents may come from teaching and research institutions in France or abroad, or from public or private research centers.
L'archive ouverte pluridisciplinaire HAL, est destinée au dépôt et à la diffusion de documents scientifiques de niveau recherche, publiés ou non, émanant des établissements d'enseignement et de recherche français ou étrangers, des laboratoires publics ou privés. 
Agron. Sustain. Dev. 29 (2009) 401-408

(C) INRA, EDP Sciences, 2009

DOI: $10.1051 /$ agro/2008061
Available online at:

www.agronomy-journal.org

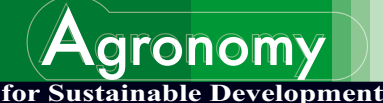

for Sustainable Development

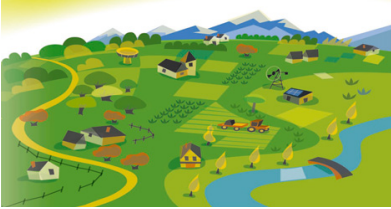

\title{
Research article
}

\section{Effect of cropping systems and crop rotations on weeds}

\author{
Alireza KoocheKI ${ }^{1}$, Mehdi NASsIRI ${ }^{1}$, Leila ALIMORADI $^{2}$, Reza GHORBANI $^{1 *}$ \\ ${ }^{1}$ Department of Agronomy, Faculty of Agriculture, Ferdowsi University of Mashhad, PO Box 91775-1163, Mashhad, Iran \\ ${ }^{2} \mathrm{PhD}$ student in Faculty of Agriculture, Ferdowsi University of Mashhad, Iran
}

(Accepted 31 October 2008)

\begin{abstract}
Dynamics of weed populations in arable fields are influenced by environmental and soil characteristics and also by cropping system and management practices. Manipulation of cropping systems to improve weed management requires a better understanding of the spatial and temporal dynamics of weeds, seed losses and seed production. To assess the effect of different cropping systems and various crop rotations on the weed population and seed bank, we conducted a field study at the experimental farm in Khorasan Agricultural Research Center, Mashhad, Iran. The experimental design was a split plot with 3 crop rotations as the main plots, and five cropping systems consisting of high-input, medium-input, low-input, organic and integrated systems applied to the sub-plots. Our results show that weed seed densities in organic and integrated cropping systems, of about 5000-6000 seeds $/ \mathrm{m}^{2}$ were higher than conventional and high-input cropping systems showing about 2000 seeds $/ \mathrm{m}^{2}$. Weed seed density in continuous winter wheat of approximately $6300 \mathrm{seeds} / \mathrm{m}^{2}$ was higher than other rotations with about 5000 seeds $/ \mathrm{m}^{2}$. Weed composition in the high-input system was 11 species with 66 plants $/ \mathrm{m}^{2}$. Whereas in the low-input and organic systems, the weed populations were 15 and 13 species with 145 and 220 plants $/ \mathrm{m}^{2}$, respectively. Changes in weed seed bank density and species composition often occur when crop management practices and crop rotations are altered. For example, continuous winter wheat fields showed more annual grass weeds, but broadleaf weeds were more abundant in sugar beet-winter wheat rotation. The weed population in continuous winter wheat plots comprised $90 \%$ grass and sedge weeds, while in sugar beet-wheat rotation, it was only $43 \%$ of total weed density. Broadleaf weeds were $55.2 \%$ in sugar beet-winter wheat but $9.4 \%$ of total weed density in continuous winter wheat. Different rotations that include crops with different life cycles such as winter wheat-maize and winter wheat-sugar beet could lead to additional benefits of reducing the weed seed bank.
\end{abstract}

conventional agriculture / ecological farming / integrated crop management / low-input crop production / organic farming

\section{INTRODUCTION}

Despite advances in control technologies, weeds have retained their rank as the most damaging of crop pests because weed communities continue to adapt in response to new management measures (Sosnoski and Cardina, 2006). In an integrated approach, the development of cropping systems such as appropriate spatial arrangement and efficient tillage will help crops themselves to compete with weeds (Avola et al., 2008). Manipulation of cropping systems for the purpose of improving integrated weed management requires a good understanding of weed dynamics and influences of crop- and soil-related factors on weed life cycles (Davis and Liebman, 2003). Weed flora have changed over the past century, with either increasing or decreasing species abundance depending on the management (Bagmet, 2000; Marshall et al., 2003; Stoate et al., 2002). Weed seed banks may reflect the status of weed population in the present and the past, and could be regarded as an indicator of the impact of soil and crop management (Buhler et al.,

* Corresponding author: ghorbani43@gmail.com
2001). However, the relationship between the weed seed bank in the soil and emerged weeds is not straightforward (Barberi et al., 1998; Forcella et al., 1996; Sjursen, 2001). Crop rotation, the tillage system, application of agrochemicals and other agricultural practices affect the soil seed bank and weed flora (Marshall et al., 2003).

Weed presence may cause more problems in some cropping systems, especially in organic farming where application of synthetic agrochemicals is not allowed. Belde et al. (2000) found that the composition of weed seed in the soil seed bank hardly changed six years after converting a farm from conventional to organic systems. However, many other investigators showed positive effects of organic agriculture on biodiversity of arable fields and grasslands (e.g. Gruber et al., 2000; Hald, 1999; Van Elsen, 2000). Mulching is one weed control strategy in mandarin orchards that also provides other benefits in terms of sustainable agriculture, such as soil protection or avoiding herbicide pollution (Verdú and Mas, 2007). In no-till systems, weed presence and diversity were often greater than in either minimum or conventional tillage (Blackshaw et al., 2001; 
Gruber et al., 2000). No-till wheat management systems with a living mulch are a possible means to improve agricultural sustainability (Carofa et al., 2007). Changes in crop rotation and herbicide use could change the weed seed banks in arable soils (Squire et al., 2000). Rotations comprised of two cool-season crops followed by two warm-season crops are the most disruptive of weed population growth. The impact of rotation design on weed community density is enhanced by no-till. Crop tolerance to weeds is improved by systems of cultural tactics. The tolerance is greatest when three tactics are combined together (Anderson, 2007). Replacing spring cereals with winter cereals resulted in a $25 \%$ reduction in weed density and species diversity (Hald, 1999). Considering plants with allelopathic effects such as rye and triticale permits sustainable weed management while reducing the impact of agriculture on the environment (Tabaglio et al., 2008). Various mechanical approaches might also be applied in different crop rotations and cropping systems. Depending on the stage of growth and type of weed, i.e. the depth at which new shoots can be formed and the ability to withstand burial, implements inflict damage on weeds in different ways such as cutting, burial or uprooting (Chicouene, 2007).

Vertical distribution of weed seeds in the soil is fundamentally important. Regardless of soil aggregate size, seed number is generally greatest in the upper $5 \mathrm{~cm}$ of soil (Reuss et al., 2001) and weed seeds in the surface layer germinate and create problems (Colbach et al., 2000). Agricultural practices change the population and composition of weeds and the soil seed bank in agro-ecosystems, although most weed management systems do not consider the impact on weed population dynamics (Davis et al., 2004). Nevertheless, the tillage system may affect the vertical distribution of seeds in the soil. For instance, Buhler et al. (2001) found that prior to moldboard tillage, weed seeds were concentrated in the upper $10 \mathrm{~cm}$ of soil. After moldboard tillage, weed seeds were uniformly distributed over the upper $20 \mathrm{~cm}$ of soil, and distribution across depth remained relatively constant during three years of maize and soybean production.

The aims of the present study were to evaluate the density and composition of the weed population and weed seed bank established after 6 years of crop rotation, under 5 cropping systems differing in type and amount of inputs. Crop rotations were continuous winter wheat, winter wheat in rotation with sugar beet and winter wheat in rotation with maize. The cropping systems range from intensive and high-input to low-input and organic farming systems. The specific goals were: (i) to highlight weed species favored by the different cropping systems and (ii) to ascertain whether organic and low-input systems might lead to the establishment of a potentially troublesome weed flora.

\section{MATERIALS AND METHODS}

Field studies were conducted at the experimental farm in Khorasan Agricultural Research Center, Mashhad, in the North-East of Iran, located at 36.20 latitude and 59.35 East longitude on silt loam soil with a $\mathrm{pH}$ of 7 to 8 and 0.2 to $0.3 \%$ organic matter prior to initiating the trial. The experimental site was characterized by an arid and semiarid continental climate, with a 286-mm average annual rainfall. The study was initiated in 1997 and maintained until 2002. The field was used to produce various crops in a 6-year rotation, using the same experimental design for all six years. The experiment was arranged in a split plot based on a completely randomized block design with three replications. Three crop rotations as the main plots " $15 \mathrm{~m}$ by $12 \mathrm{~m}$ " and five cropping systems as the sub-plots " $15 \mathrm{~m}$ by $2.4 \mathrm{~m}$ " were applied. The crop rotation variables consisted of (1) continuous winter wheat (W-W), (2) maize-winter wheat (M-W) and (3) sugar beet-winter wheat $(\mathrm{S}-\mathrm{W})$. Winter wheat, sugar beet and maize were used in the rotation because they are main crops in the region. The cropping systems consisted of (1) high-input, (2) medium-input, (3) low-input, (4) integrated and (5) organic systems (Tab. I). Inputs and agronomic practices for the five different cropping systems were chosen according to the most common practices used by farmers in the area. Weed composition and the seed bank were measured in the sixth year when the crop was winter wheat in all rotations. In the high-input, medium-input and integrated systems, plots were plowed at $30 \mathrm{~cm}$ depth in fall (early October) by a moldboard plow followed by a second harrowing tillage " $15 \mathrm{~cm}$ deep". Organic and low-input system plots were prepared simultaneously with other cropping systems through disking and leveling, while in the other three cropping systems plowing was also practiced (Tab. I). In the initial year, winter wheat for continuous winter wheat, maize for maize-winter wheat and sugar beet for sugar beet-winter wheat rotations were sown. For all years, winter wheat was sown on October 10 and sugar beet and maize were sown on May 16 and June 20, respectively. Plots were unplanted between harvesting one crop and planting another in all rotations. The crop rotation continued for 6 years from 1997 until 2002. In order to separate the effects of crop rotation and weed control methods, the first sampling date for the weed population and seed bank was in April 2002 before weeds were controlled.

Spring weed control in winter wheat plots consisted of: 1.5 $\mathrm{L}$ active ingredient $\mathrm{ha}^{-1}$ of 2,4-D for high-input, medium-

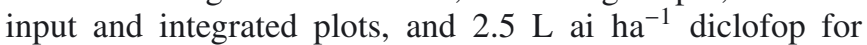
high-input plots. Weed control in sugar beet plots consisted of hand-weeding three times during the growth season for all plots, $5 \mathrm{~kg} \mathrm{ha}^{-1}$ pyrazon for high-input, medium-input and integrated plots, and $5 \mathrm{~L}$ ai ha ${ }^{-1}$ phenmedipham for high-input plots (Tab. I). Weed control in maize plots consisted of handweeding, 4 times for high-input and 3 times for the other cropping systems during the growth season (Tab. I).

At sowing time each year, NPK fertilizer was applied to all plots except the organic plots, in which $20 \mathrm{t} /$ ha cattle manure was used. Row spacing for wheat was $20 \mathrm{~cm}$ and for maize and sugar beet was $60 \mathrm{~cm}$. The differences between various cropping systems are summarized in Table I.

Weed population samples were taken on April 15, June 15 and August 152002 in the sixth year. Weed management practices in this sixth year were carried out in the middle of May and July 2002. Two quadrants of 60 by $60 \mathrm{~cm}$ were randomly 
Table I. Inputs used for different cropping systems.

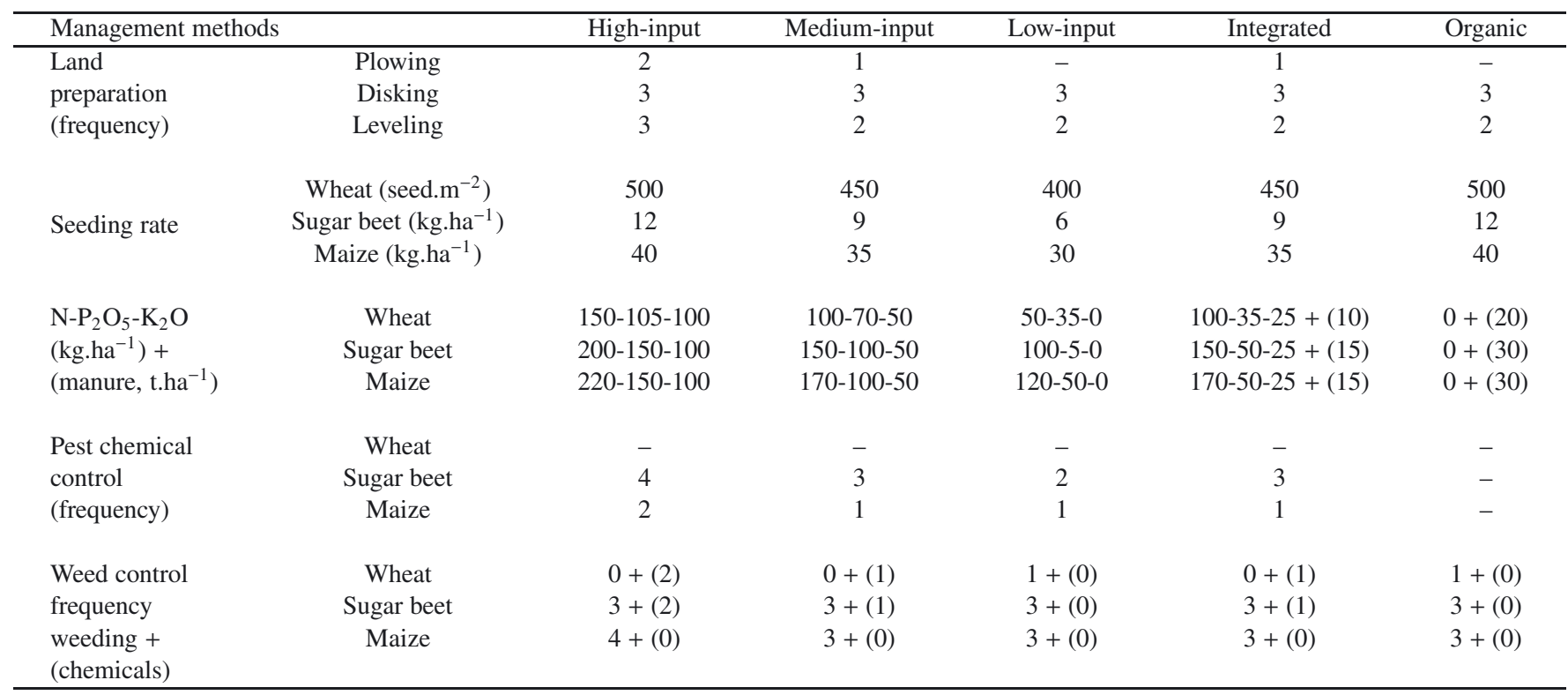

thrown in each sub-plot and weed species were counted, collected and then identified in the lab.

Soil samples were taken in April and August 2002 in the sixth year, with a $2.5-\mathrm{cm}$ diameter steel probe (Dessaint et al., 1997). Six soil core samples were taken from two depths, 0-15 and 15-30 cm, of each sub-plot and six samples at each depth were pooled and stored in plastic bags in the dark at $4{ }^{\circ} \mathrm{C}$ prior to analysis. A total of 540 soil cores " 6 samples by 2 depths by 5 cropping systems by 3 rotations by 3 blocks" were taken from the whole experiment. Soil debris such as stone pieces and root fragments was separated from soil samples and the soil was spread on 19 by $13 \mathrm{~cm}$ plastic trays with $3 \mathrm{~cm}$ soil layer thickness. Subsequently, these trays were placed on greenhouse benches with temperatures of $25^{\circ} \mathrm{C}$ day $/ 16^{\circ} \mathrm{C}$ night, for $4-5$ weeks, and watered to keep the soil at field capacity. During this period, emerged weed seedlings were identified, counted and removed. Seedlings too small to identify were either marked with coded sticks or transplanted and allowed to grow until their identity could be ensured. Then, all trays were placed at $4^{\circ} \mathrm{C}$ in the darkness for vernalization for 2 months. Ethephon 20ppm, which contains $20 \mathrm{mg}$ active ingredient per $\mathrm{kg}$ soil, was applied to the soil to stimulate germination of dormant seeds (Cardina and Sparrow, 1996). Finally, germination was again monitored for a period of 8 weeks in the conditions described previously (Belo and Dias, 1998; Caixinhas et al., 1998). Although the direct germination method requires significant time and space, there is evidence to show that it can provide a more accurate estimate of species compositions than the seed extraction method (Cardina and Sparrow, 1996).

All data were log-transformed and subjected to analysis of variance (ANOVA). Data were analyzed, using PROC MIXED with the complex symmetry model (SAS Inst., 1988) and differences between treatments were compared using Least Sig- nificant Difference (LSD) tests at the $P=0.05$ level (Gomez and Gomez, 1984).

\section{RESULTS AND DISCUSSION}

\subsection{Cropping systems and weed seed bank}

The objective was to find whether crop management ranging from low- to high-input could change weed seed bank characteristics over time. The results of the present study showed significant differences among the various cropping systems for total weed seed density in each soil layer and weed seed distribution among soil layers (Fig. 1). Actual differences between different cropping systems were more pronounced in the upper layer than in the deeper layer (Fig. 2). Weed seed densities in organic and integrated cropping systems were significantly higher than in other cropping systems in the top 15-cm soil layer in April. No herbicide application combined with the application of matured cattle manure may cause this higher soil seed density in organic systems (Benoit et al., 1992). However, reduced herbicide inputs in an integrated cropping system may lead to increased weed survival and weed seed production, which may in turn magnify crop management problems in future years. The highest seed density and species diversity in the 15 to $30 \mathrm{~cm}$ soil depth were observed in the organic system (3450 seeds $\mathrm{m}^{-2}$ from 12 species). Barberi et al. (1998) reported that weed seed bank communities were more diverse in low-input and organic systems as compared with conventional operations.

The distribution pattern of weed seeds in the soil layers varied with the management systems.

The results showed a high proportion of seeds in the upper $15 \mathrm{~cm}$ of soil, compared with the lower layer $(15-30 \mathrm{~cm})$ in organic and integrated cropping systems (Fig. 2) and a much 


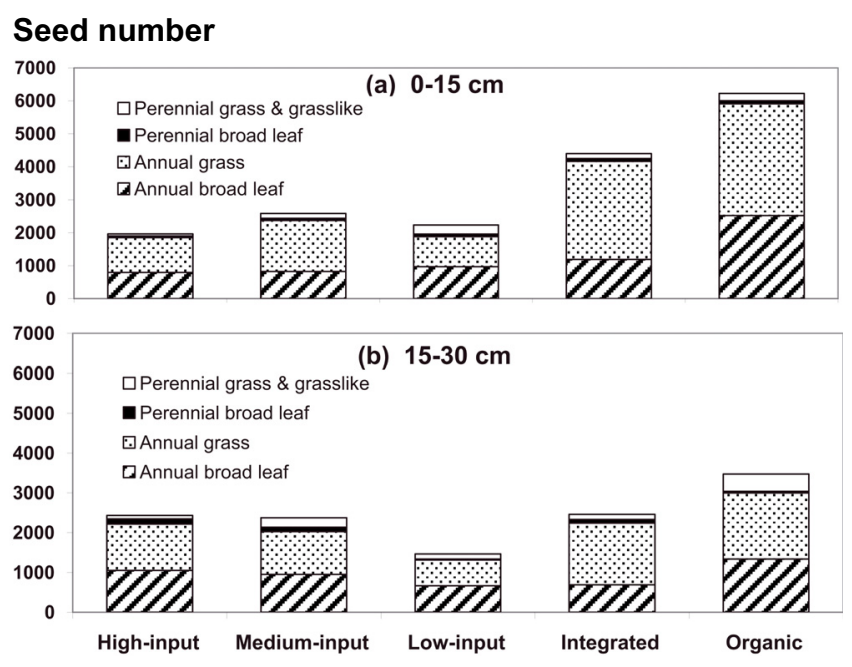

Figure 1. The effect of different cropping systems on weed seed density per $\mathrm{m}^{2}$ in the top 0 to $15 \mathrm{~cm}$ (a) and 15 to $30 \mathrm{~cm}$ (b) soil depths in April 2002, six years after study initiation, averaged across crop rotations. Least significant differences (LSD) between the means can be used to compare total seed number among systems. $\operatorname{LSD}_{0.05}=2062$ for $0-15 \mathrm{~cm}$ and $\mathrm{LSD}_{0.05}=1804$ for $15-30 \mathrm{~cm}$ soil depth.

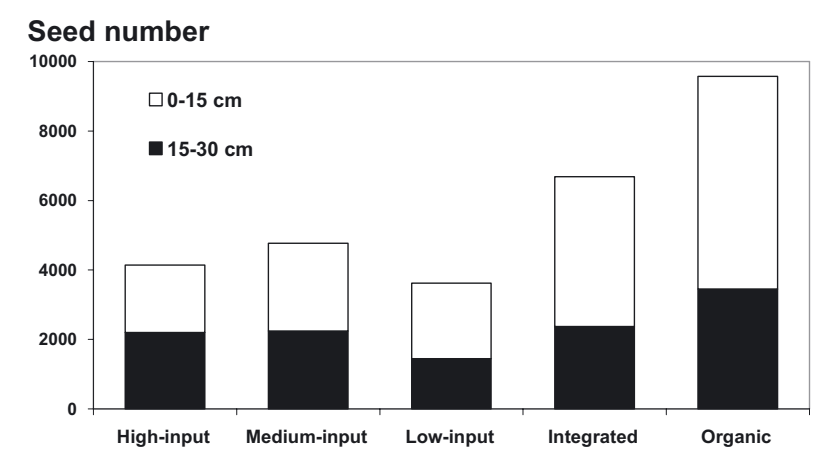

Figure 2. The effect of different cropping systems on weed seed density per $\mathrm{m}^{2}$ in different soil layers (0 to 15 and 15 to $30 \mathrm{~cm}$ soil depths) in April 2002, six years after study initiation, averaged across crop rotations. Least significant differences $\left(\mathrm{LSD}_{0.05}=2312\right)$ between the means can be used to compare total seed number among systems.

more homogeneous distribution along the profile $(0-30 \mathrm{~cm})$, in high-, medium- and low-input systems. This result was due to using conventional tillage (moldboard tillage) in these systems. Buhler et al. (2001) provide evidence that the tillage system influences weed seed distribution in the soil. They reported that in the surface layer of soils, conventional tillage incorporates seed more uniformly among various soil aggregate classes than reduced tillage; weed seeds tend to accumulate in the unaggregated soil fraction in reduced-tillage systems.

By August, the populations of weed seeds and relative abundance of the different types of weeds were different from those in April (Fig. 3), with annual broadleaf weeds more prevalent. This may have been caused by the fact that summer annual broadleaf weeds had matured and dispersed their seeds soon before sampling in August. It shows that the effects of

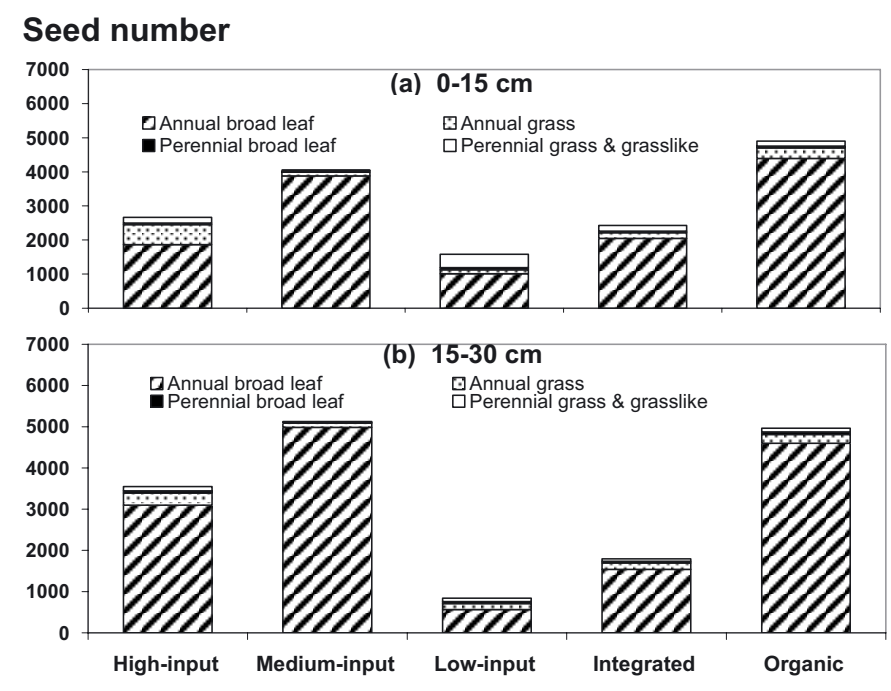

Figure 3. The effect of different cropping systems on weed seed density per $\mathrm{m}^{2}$ in the top 0 to $15 \mathrm{~cm}$ (a) and 15 to $30 \mathrm{~cm}$ (b) soil depths in August 2002, six years after study initiation, averaged across crop rotations. Least significant differences (LSD) between the means can be used to compare total seed number among systems. $\mathrm{LSD}_{0.05}=1822$ for $0-15 \mathrm{~cm}$ and $\mathrm{LSD}_{0.05}=1211$ for $15-30 \mathrm{~cm}$ soil depth.

poor weed control in a single season may outweigh the longterm effects of different rotations and cropping systems.

\subsection{Cropping systems and weed population}

In addition to weed seed bank characteristics, the population of weeds was also targeted after six years of management under different cropping systems. Effects of cropping systems on weed populations differed between sampling times. In April, the highest weed density of weeds was observed in organic and medium-input cropping systems (Fig. 4). The lowest weed seed density was observed in the high-input cropping system, which could be attributed to effective weed control through herbicide application in previous years. Herbicides reduce weed densities and indirectly reduce weed seeds in the seed bank. Barberi et al. (1998) also reported that in their study, the conventional system bore the lowest number of weeds. Weed density and composition in the high-input system was 11 species with 66 plants $\mathrm{m}^{-2}$ and in the low-input and organic systems, the weed populations were 15 and 13 species with 145 and 220 plants $\mathrm{m}^{-2}$, respectively. The annual grasses and annual broadleaf weeds were the most prevalent species. Higher crop density in high-input systems, leading to a vigorous, highly competitive crop canopy, may have resulted in more effective weed suppression and lowered weed density in the system (Norris et al., 2001).

The results of the second sampling (June) showed that the organic and low-input systems had the highest population of perennial weeds (Fig. 4). Emergence of perennial weeds could be due to lack of chemical herbicides and also low levels of disturbance of soil in the organic and low-input systems 


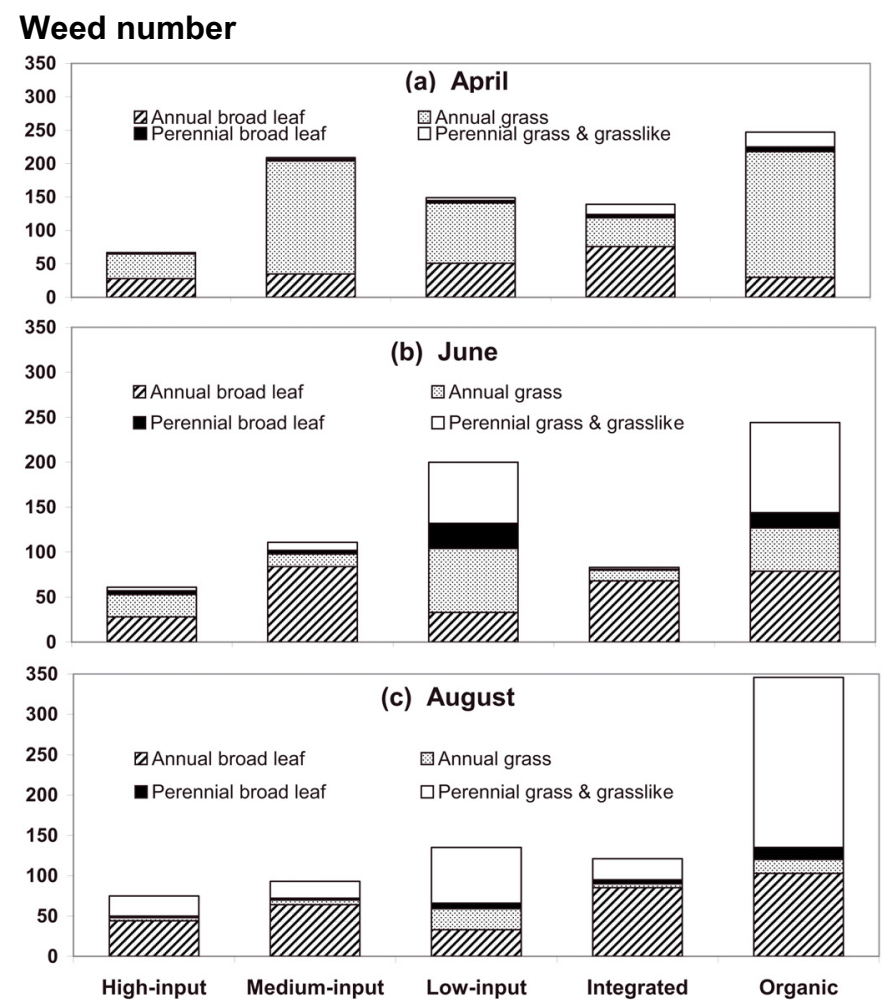

Figure 4. The effect of different cropping systems on weed population per $\mathrm{m}^{2}$ in April (a), June (b) and (c) August 2002, six years after study initiation, averaged across crop rotations. Least significant differences (LSD) between the means can be used to compare total weed number among systems. $\mathrm{LSD}_{0.05}=58.9$ for April, $\mathrm{LSD}_{0.05}=62.9$ for June and $\mathrm{LSD}_{0.05}=64.2$ for August.

(Tab. I). Shares of annual broadleaf weeds in the high-input, medium-input and integrated systems were 48.5, 77.6 and 83.7 percent, respectively.

In August, organic system plots had the highest and most diverse weed density ( 345 plants $\mathrm{m}^{-2}$ and 18 species). Although there were differences in weed density and composition, the differences became more pronounced as the season progressed. In the organic and low-input systems perennial weeds accounted for 66 and $56 \%$ of the total weed population, respectively. This could be associated with a lower tillage level applied for seed-bed preparation in these cropping systems. Greater prevalence of perennial weeds in minimum tillage has been reported in the literature (Dawit and David, 1997). In contrast, perennial weed populations increase in reduced tillage systems because the root system is not disturbed (Buhler et al., 1994). In high-input systems, perennial weeds were less frequent (Fig. 4). Barberi et al. (1998) reported that frequent seed-bed preparation and high level of tillage practices decreased perennial weeds. Sosnoski et al. (2006) concluded that long-term changes in weed flora were driven by interactions between disturbance, the environment, and the timing and type of weed management practices. This study showed that organic and low-input systems are most likely to

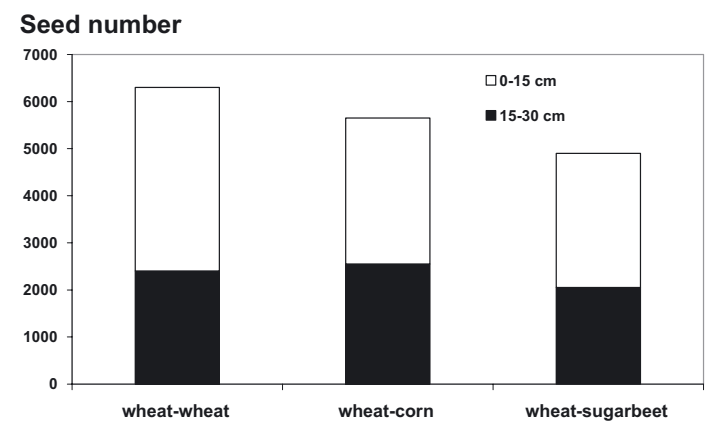

Figure 5. The effect of different crop rotations on weed seed density per $\mathrm{m}^{2}$ six years after study initiation. All results are averaged over April, June and August 2002 and over crop management systems. Least significant differences $\left(\mathrm{LSD}_{0.05}=1401\right)$ between the means can be used to compare total seed number among rotations.

lead to higher weed seed density, weed population and establishment of potentially perennial, trouble some weeds.

\subsection{Crop rotation and weed seed bank}

Another main objective in this study was evaluation of the effect of three different crop rotations after 6 years on weed flora. The structure of the current species in the weed community or weed seed bank is influenced by the crops that are part of the rotation. Seed density in the rotations of wheatsugar beet was lower than under continuous wheat. In rotation of sugar beet-winter wheat the seed density in soil was lower $\left(4500 \mathrm{seeds} / \mathrm{m}^{2}\right)$ than in other rotations and this rotation caused $28 \%$ reduction in the weed seed bank. Rotation of maize-winter wheat caused $12 \%$ reduction in the seed bank compared with continuous wheat. Therefore, broadleaf crops in rotation with narrow-leaf crops and also crops with different agronomic practices can reduce the weed seed bank density. Density of the seed bank in plots with continuous wheat was higher in the upper layer $(0-15 \mathrm{~cm})$ than the deeper soil layer $(15-30 \mathrm{~cm})$ compared with other rotations. In plots with continuous wheat, out of a total of 6310 seeds per $\mathrm{m}^{2}$, $62 \%$ (3877 seeds $/ \mathrm{m}^{2}$ ) were in the $0-15 \mathrm{~cm}$ soil layer (Fig. 5). This could be because of different agronomic practices such as tillage and cultivation and other management practices of various consecutive crops which could affect weed flora, and so weed density. Ball and Miller (1990) reported that crop rotation is one of the important factors that affect weed populations. Crop rotation influences the herbicides available for use, type of tillage, time of tillage events relative to crop and weed emergence, and harvest date relative to crop and weed maturity. These agronomic practices influenced weed species composition over a period of six growing seasons.

\subsection{Crop rotation and weed population}

Changes in weed flora under the effect of three different crop rotations were also investigated. In continuous wheat 
Table II. Weed density (number.m ${ }^{-2}$ and as \% total) in different crop rotations. All results are averaged over April, June and August 2002 and over crop management systems.

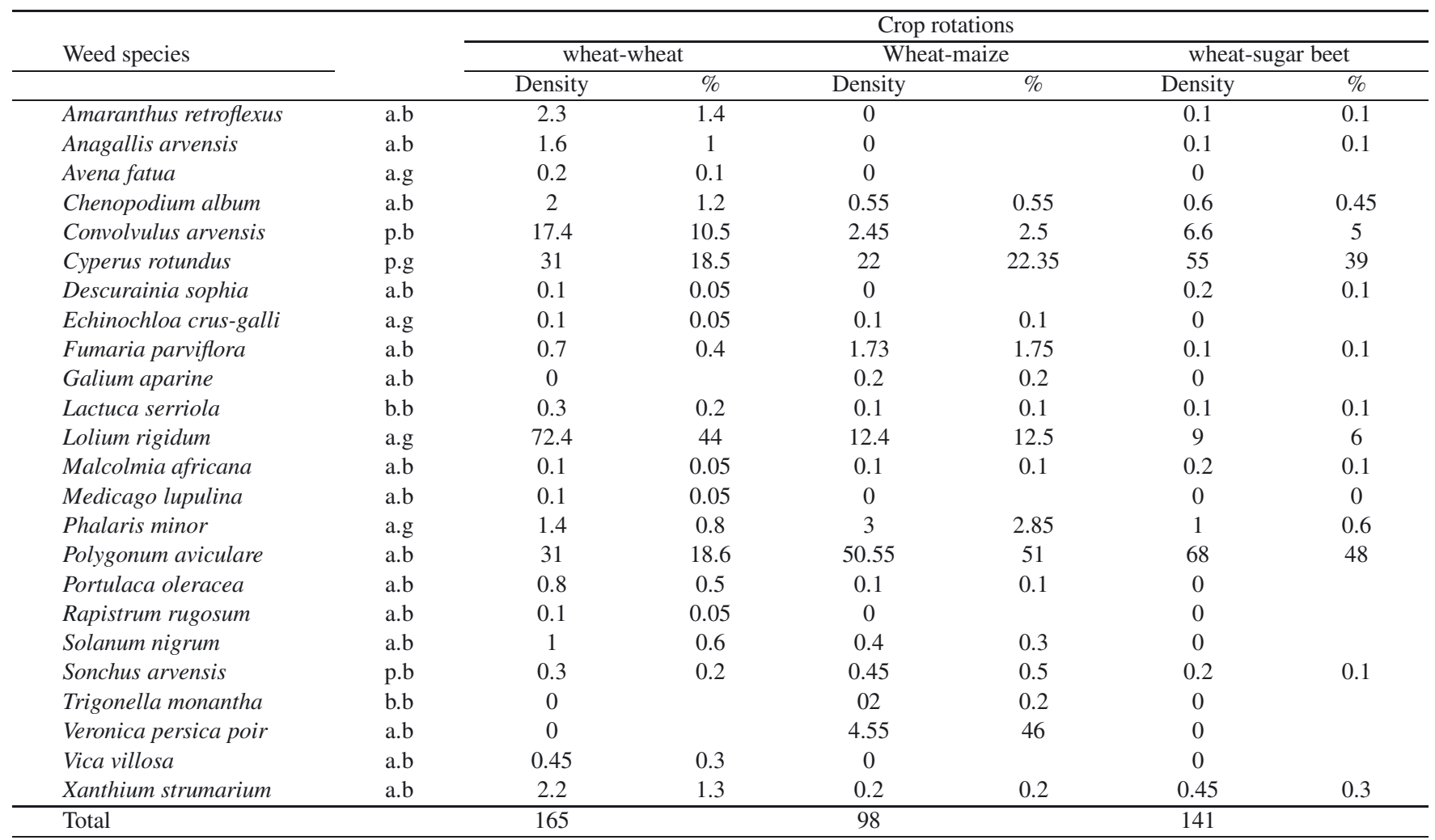

* ab (annual broadleaf), pb (perennial broadleaf), bb (biennial broadleaf), ag (annual grass), pg (perennial grass or sedge).

\section{Weed number}

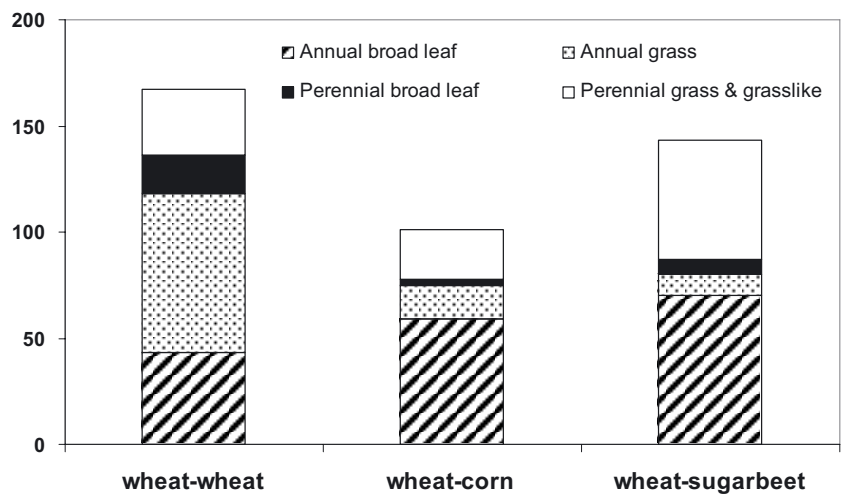

Figure 6. The effect of different crop rotations on weed population density per $\mathrm{m}^{2}$. All results are averaged over April, June and August 2002 and over crop management systems, six years after study initiation. Least significant differences (LSD $=53.1$ ) between the means can be used to compare total weed number among rotations.

fields, the annual grasses were more prevalent than in the other rotation systems (Tab. II, Fig. 6). Weed population in early spring (April) was highest in continuous wheat plots compared with other rotations. Weed population in continuous winter wheat plots comprised $90 \%$ grass and sedge weeds, while in sugar beet-wheat rotation, it was only $43 \%$ of total weed density. Although seed banks and the resulting weed population are composed of many species, generally a few dominant species comprise $70 \%$ to $90 \%$ of the total seed bank. These dominant species are the primary pests because they are resistant to control measures or adapted to the cropping systems (Buhler et al., 2001).

Broadleaf weeds were $55.2 \%$ in sugar beet-winter wheat, but $9.4 \%$ of total weed density in continuous winter wheat. It appears that morphological similarity of the crops and weeds influenced the type of weed species present (Derksen et al., 1993). Liebman and Dyck (1993) demonstrated that monoculture can lead to a less diverse and more intractable weed flora than crop rotation. Therefore, the structure of the current species in a seed bank is influenced by the crops that are part of the rotation.

Species such as ryegrass (Lolium rigidum L.) and canarygrass (Phalaris minor L.) were more prevalent in continuous winter wheat, while fumitory (Fumaria parviflora L.), ryegrass, flixweed (Descurainia sophia L.) and barnyardgrass (Echinochloa crusgalli L.) were dominant in maize-winter wheat, and knotweed (Polygonum aviculare L.), ryegrass, fumitory and flixweed were mostly abundant in sugar beetwinter wheat rotations. Weed density and composition were different in various crop rotations (Tab. II). In continuous 
wheat fields, 21 species with a density of 165 plants $\mathrm{m}^{-2}$, in maize-winter wheat, 17 species with 98 plants $\mathrm{m}^{-2}$ and in

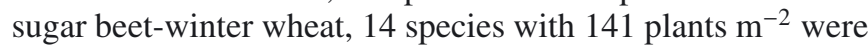
observed. Annual broadleaf weeds were dominant ( 8 species with $49 \%$ relative density) in sugar beet-wheat rotation. However, annual grasses constituted 4 species with $45 \%$ of total weed density in wheat-wheat plots, 3 species with $15 \%$ of density in maize-wheat and 2 species with $6.6 \%$ of the density in sugar beet-wheat. This trend should be related to emergence of new weed species in that season (Doucet et al., 1999). In this study, double-species crop rotations reduce opportunities for weed growth and regeneration through resource competition and niche disruption.

\section{CONCLUSION}

Our results showed that organic and low-input systems were more weed-infested. However, this result came from a field with only 6 years of history, and weed population might be different in a field with a longer history of low-input management. Weed management practices such as tillage and application of organic amendments can change the incidence and severity of weed density and the weed community competition in long-term management, unless other effective alternative treatments for chemical herbicides are found. Continuous winter wheat fields showed more annual grass weeds, but broadleaf weeds were more abundant in sugar beet-winter wheat rotation. Long and diverse crop rotations with careful weed control in low-input and organic systems are fundamental in sustainable and ecological crop production systems. Weed management in sustainable agriculture is one of the costand time-effective factors. This finding suggests that the weed seed bank and population could in time grow even worse in sustainably-managed systems. Therefore, both cropping system and crop rotation strategies are fundamentally significant considerations in development of sustainable and environmentally safe strategies for weed control.

\section{REFERENCES}

Anderson R.L. (2007) Managing weeds with a dualistic approach of prevention and control. A review, Agron. Sustain. Dev. 27, 13-18.

vAvola G., Tuttobene R., Gresta F., Abbate V. (2008) Weed control strategies for grain legumes, Agron. Sustain. Dev. 28, 389-395.

Bachthaler G. (1974) The development of the weed flora after several years direct drilling in cereal rotation on different soils, Proceeding of the 12th British Weed Control Conference, pp. 1063-1071.

Bagmet L. (2000) Dynamic of the segetal element of weed flora in the Lower-Volga region, Z. Pflanzenk. Pflanzen. 17, 85-90.

Ball D.A. (1992) Weed seed bank response to tillage, herbicide and crop rotation sequence, Weed Sci. 40, 654-656.

Ball D.A., Miller S.D. (1990) Weed seed population response to tillage and herbicide use in three irrigated cropping sequences, Weed Sci. $38,511-517$.

Barberi P., Cozzani A., Macchia M., Bonari E. (1998) Sample size and composition of the weed seed bank under different management systems for continuous maize cropping, Weed Res. 38, 319-334.
Belde M., Mattheis A., Sprenger B., Albrecht H. (2000) Long-term development of yield affecting weeds after the change from conventional to integrated and organic farming, Z. Pflanzenk. Pflanzen. Special Issue 17, 291-301.

Belo A.F., Dias L.S. (1998) Changes in grass-weed seed banks in relation to crops and rotations, in: Champion G.T., Grundy A.C., Jones N.E., Marshall E.J.P., Froud-Williams R.J. (Eds.), Aspects of Applied Biology 51, Weed Seed Banks: Determination, Dynamics and Manipulation, pp. 221-228. Publ. Association of Applied Biologists, C/O Horticulture Research International Wellesbourne, Warwick, UK.

Benoit D.L., Derksen D.A., Panneton B. (1992) Innovative approach to seed bank studies, Weed Sci. 40, 660-669.

Blackshaw R.E., Larney F.J., Lindwall C.W., Watson P.R., Derksen D. (2001) Tillage intensity and crop rotation affect weed community dynamics in a winter wheat cropping system Can. J. Plant Sci. 81, 805-813.

Buhler D.D. (1995) Influences of tillage systems on weed population dynamics and management in maize and soybean in the central USA, Crop Sci. 35, 1247-1258.

Buhler D.D., Stoltenberg D.E., Becker R.L., Gunsolus J.L. (1994) Perennial weed populations after 14 years of variable tillage and cropping practices, Weed Sci. 42, 205-209.

Buhler D.D., Kohler K.A., Thompson R.L. (2001) Weed seed bank dynamics during a five-year crop rotation, Weed Technol. 15, $170-176$.

Caixinhas M.L., Jeronimo A., Rocha, F., Leitao A. (1998) Relationship between the seed bank and actual weed flora in an agricultural soil in the Tapada da Ajuda (Lisbona), in: Champion G.T., Grundy A.C., Jones N.E., Marshall E.J.P., Froud- Williams R.J. (Eds.), Aspects of Applied Biology 51, Weed Seed Banks: Determination, Dynamics and Manipulation, pp. 51-57. Publ. Association of Applied Biologists, C/O Horticulture Research International Wellesbourne, Warwick, UK.

Cardina J., Sparrow D.H. (1996) A comparison of methods to predict weed seedling populations from the soil seed bank, Weed Sci. 44, 46-51.

Carofa M., Tourdonneta S., Saulasb P., Flocha D.L., Roger-Estradea J. (2007) Undersowing wheat with different living mulches in a notill system. II. Competition for light and nitrogen, Agron. Sustain. Dev. 27, 357-365.

Chicouen D.E. (2007) Mechanical destruction of weeds, A review, Agron. Sustain. Dev. 27, 19-27.

Colbach N., Roger-Estrade J., Chauvel B., Caneill J. (2000) Modelling vertical and lateral seed bank movements during mouldboard plowing, Eur. J. Agron. 13, 111-124.

Davis A.S., Liebman M. (2003) Cropping system effects on giant foxtail (Setaria faberi) demography: I. Green manure and Tillage timing, Weed Sci. 51, 919-929.

Davis A.S., Dixon P.M., Liebman M. (2004) Using matrix models to determine cropping system effects on annual weed demography, Ecol. Appl. 14, 655-668.

Dawit M., David S.E. (1997) Weed and seed bank management with integrated methods as influenced by tillage, Weed Sci. 45, 706-715.

Derksen D.A., Lafond G.P., Thomas A.G., Loeppky H.A., Swanton C.J. (1993) Impact of agronomic practices on weed communities: tillage systems, Weed Sci. 41, 409-417.

Dessaint F., Chadoeuf R., Barallis G. (1997) Nine year's soil seed bank and weed vegetation relationships in an arable field without weed control, J. Appl. Ecol. 34, 123-130.

Doucet C., Hamill A.S. (1999) Separating the effects of crop rotation from weed management on weed density and diversity, Weed Sci. 47, 729-735. 
Forcella F., Durgan B.R., Buhler D.D. (1996) Management of weed seed bank in: Proceedings of Second International Weed Control Congress, pp. 123-130, Copenhagen, Denmark.

Gomez K., Gomez A. (1984) Statistical procedures for agricultural research, John Wiley and Sons, New York, USA, pp. 24-29.

Gruber H., Haendel K., Broschewitz B. (2000) Influence of farming system on weeds in thresh crops of a six-year crop rotation, Z Pflanzenk. Pflanzen. Special Issue 17, 33-40.

Hald A.B. (1999) Weed vegetation (wild flora) of long established organic versus conventional cereal fields in Denmark, Ann. Appl. Biol. 134, 307-314.

Liebman M., Dyck E. (1993) Crop rotation and intercropping strategies for weed management, Ecol. Appl. 3, 92-122.

Martin R.J., Felton W.L. (1993) Effect of crop rotation, tillage practice, and herbicides on the population dynamics of wild oats in wheat, Aust. J. Exp. Agr. 53, 159-165.

Marshall E.J.P., Brown V.K., Boatman N.D., Lutman P.J.W., Squire G.R., Ward L.K. (2003) The role of weeds in supporting biological diversity within crop fields, Weed Res. 43, 77-89.

Norris R.F., Elmore C.L., Rejmanek M., Akey W.C. (2001) Spatial arrangement, density and competition between barnyardgrass growth and seed production, Weed Sci. 49, 69-76.
Reuss S.A., Buhler D.D., Gunsolus J. (2001) Effects of soil depth and aggregate size on weed seed distribution and viability in a silt loam soil, Appl. Soil Ecol. 16, 209-217.

Sjursen H. (2001) Change of the weed seed bank during the first complete six-course crop rotation after conversion from conventional to organic farming, Biol. Agric. Hortic. 19, 71-90.

Squire G.R., Rodgers S., Wright G. (2000) Community-scale seed bank response to less intense rotation and reduced herbicide input at three sites, Ann. Appl. Biol. 136, 47-57.

Sosnoski L.M., Cardina J. (2006) Weed seedbank community composition in a 35-yr-old tillage and rotation experiment, Weed Sci. 54, 263-273.

Stoate C., Boatman D., Borralho R.J., Carvalho C.R., Desnoo G.R., Eden P. (2002) Ecological impacts of arable intensification in Europe, J. Environ. Manage. 63, 337-365.

Tabaglio V., Gavazzi1 C., Schulz M., Marocco1 A. (2008) Alternative weed control using the allelopathic effect of natural benzoxazinoids from rye mulch, Agron. Sustain. Dev. 28, 397-401.

Van Elsen T. (2000) Species diversity as a task for organic agriculture in Europe, Agr. Ecosyst. Environ. 77, 101-109.

Verdú A.M., Mas M.T. (2007) Mulching as an alternative technique for weed management in mandarin orchard tree rows, Agron. Sustain. Dev. 27, 367-375. 